\title{
Gold catalysis for organic synthesis
}

\author{
F. Dean Toste
}

\section{Editorial}

\section{Address:}

Department of Chemistry, University of California, Berkeley, CA,

United States

Email:

F. Dean Toste - fdtoste@berkeley.edu
Beilstein J. Org. Chem. 2011, 7, 553-554.

doi:10.3762/bjoc. 7.63

Received: 28 April 2011

Accepted: 28 April 2011

Published: 04 May 2011

This article is part of the Thematic Series "Gold catalysis for organic synthesis".

Guest Editor: F. D. Toste

(C) 2011 Toste; licensee Beilstein-Institut.

License and terms: see end of document.
The past decade has witnessed a remarkable growth in the number of organic reactions that are catalyzed by homogeneous gold complexes. Many of the early reported reactions took advantage of the propensity of gold complexes to serve as excellent catalysts for reactions that proceed through $\pi$-activation of carbon-carbon multiple bonds. Subsequently, the reactivity paradigms available for gold complexes have proven to be almost limitless. The contributions from over 25 research groups from 13 countries underscore the growing importance of homogenous gold catalysis. More importantly, the papers in this Thematic Series highlight the remarkable breath of reactivity that can be accessed using homogenous gold complexes as catalysts; from catalysis of sigmatropic rearrangement, cycloaddition and cycloisomerization reactions, to applications in enantioselective catalysis, oxidative coupling and the total synthesis of natural products, and transformations of alkynes, allenes, alkenes and even $\mathrm{C}-\mathrm{H}$ bonds. A true treasure chest of reactivity!

I am grateful to all of the authors that have contributed to this Thematic Series. I hope you enjoy reading of their achievements as much as I have.

F. Dean Toste

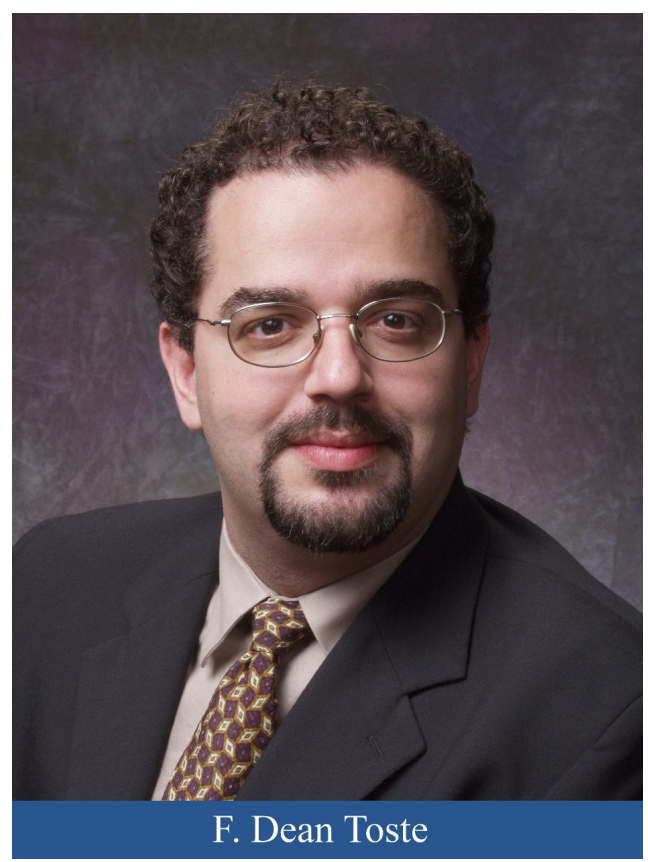

Berkeley, April 2011 


\section{License and Terms}

This is an Open Access article under the terms of the Creative Commons Attribution License

(http://creativecommons.org/licenses/by/2.0), which permits unrestricted use, distribution, and reproduction in any medium, provided the original work is properly cited.

The license is subject to the Beilstein Journal of Organic Chemistry terms and conditions:

(http://www.beilstein-journals.org/bjoc)

The definitive version of this article is the electronic one which can be found at:

doi:10.3762/bjoc.7.63 